\title{
A study on the threshold effect of different types of environmental regulations on FDI
}

\author{
Kuanqi Du ${ }^{a^{*}}$, Mengmeng $\mathrm{Li}^{b}$ \\ ${ }^{a}$ Nanjing University of Science and Technology, China \\ ${ }^{\mathrm{b}}$ Nanjing University of Science and Technology; \\ China-Decision Making and Consulting Research Center for Industrial Cluster, China \\ *Corresponding author: Kuanqi Du,professor email:almonnjust@126.com
}

\begin{abstract}
The environmental regulations are divided into three types including command-control (CER), market-incentive (MER) and public-participation (PER) in this paper. Based on the panel data in 30 provinces, cities and autonomous regions in China from 2003 to 2014, the threshold plate regression model was used to empirically test the threshold effect of different types of environmental regulations on FDI. The results are as follows: There are threshold effects on the impact of environmental regulations on FDI, an inverted U-type relationship between CER and PER and FDI, and a U-type relationship between MER and FDI. However, there is spatial heterogeneity in the impact of environmental regulations on FDI, wherein the results of the threshold effect in eastern regions are similar to those of the whole country. The impact of different types of environmental regulations on FDI in the central and western regions is not obvious with no threshold effect.
\end{abstract}

Key words: types of environmental regulations; FDI; threshold effect

\section{Introduction}

With the deepening of reform and opening up, the scale of foreign direct investment (FDI) of China attracted from overseas is on the rise. According to the statistics of China Foreign Investment Report, the scale of FDI in 2015 reached a record high with the manufacturing causing major pollution attracting large foreign investment. the actual utilization of foreign capital was 126.667 billion dollars, ranking first for 24 consecutive years among developing countries. However, while FDI is providing driving force for the development of China through channels such as capital and technology, the issue of environmental pollution is worsening day by day. To tackle the increasingly prominent environmental problems, China's government has introduced a series of more stringent and diversified environmental regulations policies. The CER is gradually transferred into three-in-one environmental regulation policy system including CER, MER and PER. According to "pollution haven hypothesis", pollution-intensive enterprises often transferred to a less restrictive countries or regions to avoid their own strict environmental regulations. According to "porter hypothesis", a reasonable environmental regulation policy can improve the attraction of FDI and realize the win-win situation of environmental protection and economic development. Is China becoming a "pollution haven"? Or has achieved the win-win situation of "porter hypothesis"? Different environmental regulations have various mechanisms. Is there a dramatic difference in the impact of FDI? 


\section{Literature review}

At present, many scholars have discussed the relationship between environmental regulations and FDI. The main points are as follows: first, environmental regulations have a negative effect on FDI, namely, the "pollution haven hypothesis" supported by some scholars. Under the established conditions, a strict environmental regulation policy will increase production cost, while a less restrictive one can significantly reduce cost. Thus, to maximize profits, enterprises will transfer to the countries or regions with a lower level of environmental regulations which has a strong attraction for $\mathrm{FDI}^{1 \sim 2}$. Second, environmental regulations have a positive effect on the inflow of FDI, namely, the Porter Hypothesis supported by others. From a dynamic point of view, a well-designed environmental regulation policy will drive companies to make technological innovation, thus reducing their production cost. With the help of innovation compensation and pioneering advantage, environmental regulations can improve the competitiveness of enterprises and has a positive effect on $\mathrm{FDI}^{3-5}$. Third, the impact of environmental regulations on FDI is little or even none, namely, environmental regulations are not a major factor affecting $\mathrm{FDI}^{6-9}$. Forth, environmental regulations and FDI may not be a simple linear relationship, but a significant nonlinear relationship. The impact of environmental regulations on FDI is related to the regional heterogeneity of investment and the industrial heterogeneity. The high or low intensity of environmental regulations is not beneficial to the introduction of FDI. Only within the optimal regulatory range can FDI inflows $^{10-12}$.

From the perspective of the research on the existing literature at home and abroad, the scholars have conducted a more comprehensive study on the relationship between environmental regulations and FDI, but their studies regard environmental regulations as the intensity of regulations as a whole without distinguishing the types of environmental regulations. Moreover, in the method of estimating the nonlinear relationship between environmental regulations and FDI, exogenous sample separation method is adopted in most of the literature, which will cause deviation of the estimated result due to the subjective judgment of the environmental regulation range. Thus, in this paper, the three types of environmental regulations including CER, MER and PER are included into the environmental regulation evaluation system to test the impact of them on FDI, respectively. In the research method, the threshold panel regression model proposed by Hansen (1999) ${ }^{13}$ is adopted and the threshold is determined internally based on the characteristics of the data itself.

\section{Research design}

\subsection{The setting of econometric model}

In this part, with FDI as explained variables, CER, MER and PER as core explanatory variables, and other factors affecting FDI as control variables, the empirical study is conducted to test the impact of environmental regulations on FDI, which is also a basis for further testing and analyzing threshold effect. To facilitate the comparison of data and ensure the stability of results, all variables in this paper are logically processed. The panel regression model is as follows:

$$
\ln F D I_{i t}=\beta_{0}+\beta_{1} \ln C E R_{i t}+\beta_{2} \ln M E R_{i t}+\beta_{3} \ln P E R_{i t}+\beta_{2} \ln P G D P_{i t}+\beta_{3} \ln T R A D E_{i t}+\beta_{4} \ln W A G E_{i t}+\varepsilon_{i t}
$$


Wherein, $i$ is represents provinces $(\mathrm{i}=1,2,3 \ldots, 30) . t$ is time. $F D I_{i t}$ is foreign direct investment. $C E R_{i t}, M E R_{i t}$ and $P E R_{i t}$ are the intensity of CER, MERand PER, respectively. $P G D P_{i t}$ is per capita GDP. TRADE $E_{i t}$ is foreign trade level. $W A G E_{i t}$ is labor cost. $\beta_{0}$ is intercept. $\beta_{1} \sim \beta_{4}$ are parameters to be estimated, $\varepsilon_{i t}$ is allowed error.

\subsection{Data source and variable description}

The sample is the panel data from 2003 to 2014 in the 30 provinces(excluding Tibet), cities and autonomous regions in China which are divided into eastern, central and western regions (The eastern region includes Beijing, Anhui, Tianjin, Zhejiang, Fujian, Hebei, Liaoning, Shanghai, Jiangsu, Shandong, Guangdong, Hainan. The central region includes Shanxi, Jilin, Heilongjiang, Jiangxi, Henan, Hubei and Hunan. The western region including Inner Mongolia, Guangxi, Sichuan, Chongqing, Gansu, Qinghai, Guizhou, Yunnan, Shanxi, Ningxia, Xinjiang; Because of the lack of data in some years in Tibet, the data is deleted in the measurement process, taking into account the continuity of data) in accordance with the division criteria of 2015 "China Statistical Yearbook". The relevant data are mainly from the "China Statistical Yearbook", "China Environment Yearbook", "China Environmental Statistical Yearbook" and the local statistical yearbook over the years. Some missing data in this paper are supplemented by linear regression extrapolation and linear interpolation. All indicators related to the price index are reduced by the relevant price index with the year of 2003 as the base period. The relevant variables are specified as follows:

\subsubsection{Foreign Direct Investment (FDI)}

As the data unit provided by official statistics is in US dollars, FDI, directly represented by the actual amount of foreign direct investment in the 30 provinces, cities and autonomous regions, is converted into RMB in line with the annual average exchange rate of RMB against the U.S. dollar.

\subsubsection{Measurement of Environmental Regulations}

On the basis of the study conducted by Zhao Yuming (2009) ${ }^{14}$ and Zhan Jia (2015) ${ }^{15}$, environmental regulations are divided into three types including CER, MER and PER in accordance with implementation mechanism.

(1) Command-Control Environmental Regulation (CER). the intensity of CER is measured with reference to the index construction method of Levinson $(2002)^{16}$ based on the amount of environmental investment with "three simultaneousness" of design, construction and production, the per unit of industrial output in the 30 provinces, cities and autonomous regions of which $\left(s_{i t}\right)$ is as follows:

$$
S_{i t}=\frac{P_{i t}}{Y_{i t}}
$$

Wherein, $P_{i t}$ is the amount of environmental investment with "three simultaneousness" completed by province $i$ in the year of $t . Y_{i t}$ is the total output of industrial enterprises above designated size in province $i$ in the year of $t$. As there are obvious differences in the industrial structure in the 30 provinces, cities and autonomous regions, if the per unit of industrial output of the amount of environmental investment with "three simultaneousness" is used to evaluate the environmental regulation level, the regulation level of pollution-intensive 
industries concentrated provinces will be overestimated, while underestimating the regulation level of clean-up industries. Thus, The proportion of industrial output in each province to GDP, namely, the industrial structure $\left(S_{t}\right)$, is used to revise $\left(S_{i t}\right)$. The result is shown in formula (3):

$$
C E R_{i t}=\frac{S_{i t}}{S_{t}} * 100
$$

The greater the $C E R_{i t}$ is, the higher intensity of environmental regulations.

(2) Market-Driven Environmental Regulation (MER). The pollution-discharge fee system exercised nationwide since 2003 is utilized to represent MER. Total amount of pollutiondischarge fees in the 30 provinces, cities and autonomous regions are used to measure the intensity of environmental regulations. Specific processing method is with the CER.

(3) Public-Participation Environmental Regulation (PER). Environmental letters and visits in are used to measure PER. As the behavior of public participation will be influenced by the education level and the total amount of population, the proportion of population with high school education in each province and autonomous regions to those nationwide is regarded as adjustment factor.

\subsubsection{Other Control Variables}

Provincial gross domestic product (PGDP) is represented by the per capita GDP in each province (cities).Labor cost (WAGE) is represented by the average wages of workers in each province (cities).Foreign trade level is represented by total import and export trade and also converted into RMB in line with the annual average exchange rate of RMB against the U.S. dollar.

\section{An Empirical analysis of the impact of different types of environmental regulations on FDI}

Table 1- Metrological Regression Results of National Overall Samples and Regional Samples

\begin{tabular}{|c|c|c|c|c|}
\hline Explanatory Variable & Overall & Eastern Region & Central Region & Western Region \\
\hline \multirow{2}{*}{$\operatorname{lnCER}$} & $0.0151^{* * *}$ & $0.03668^{* * *}$ & -0.0012 & $-0.0091^{* * *}$ \\
& $(2.85)$ & $(3.15)$ & $(-0.19)$ & $(-2.67)$ \\
\hline \multirow{2}{*}{ LnMER } & $-0.0181^{* * *}$ & $-0.0300 * *$ & $-0.0198^{* * *}$ & 0.0043 \\
& $(-3.13)$ & $(-2.55)$ & $(-2.61)$ & $(1.07)$ \\
\hline \multirow{2}{*}{$\ln$ PER } & $-0.0078^{* * *}$ & $-0.0085^{* *}$ & -0.0032 & $-0.0020^{*}$ \\
& $(-4.71)$ & $(-2.34)$ & $(-1.45)$ & $(-1.96)$ \\
\hline \multirow{2}{*}{$\operatorname{lnPGDP}$} & $0.7785^{* * *}$ & $0.8143^{* * *}$ & $0.7599^{* * *}$ & $0.8705^{* * *}$ \\
& $(24.49)$ & $(13.08)$ & $(16.24)$ & $(38.70)$ \\
\hline \multirow{2}{*}{$\operatorname{lnTRADE}$} & $0.3164^{* * *}$ & $0.2821^{* * *}$ & $0.4062^{* * *}$ & $0.33487^{* * *}$ \\
& $(4.45)$ & $(1.50)$ & $(3.99)$ & $(8.69)$ \\
\hline \multirow{2}{*}{$\ln$ WAGE } & $0.1847^{* * *}$ & $0.2070^{* * *}$ & $0.1229^{* * *}$ & $0.0899^{* * *}$ \\
& $(6.58)$ & $(3.64)$ & $(3.66)$ & $(4.19)$ \\
\hline \multirow{2}{*}{ cons } & $2.5324^{* * *}$ & $2.8452^{* * *}$ & $2.9927^{* * *}$ & $1.6795^{* * *}$ \\
\hline R & $(9.23)$ & $(2.81)$ & $(8.20)$ & $(15.83)$ \\
\hline Accompanying & 0.9947 & 0.9919 & 0.9987 & 0.9991 \\
\hline Probability (Statistic F) & $\mathrm{P}=0.0000$ & $\mathrm{P}=0.0000$ & $\mathrm{P}=0.0000$ & $\mathrm{P}=0.0000$ \\
\hline
\end{tabular}

Note: The data in parentheses are t. ${ }^{* * *},{ }^{* *}$ and $*$ are significantly at $1 \%, 5 \%$ and $10 \%$, respectively. 
In this paper, the software stata14.0 is used to test the impact of different types of environmental regulations on FDI. Before panel data regression, the P value of Hausman result is 0.0000 , namely, rejecting random effect. Thus, the fixed effects model is to carry out the empirical analysis. The result is as table 1.

The estimated results of national overall samples at Table 1 show that CER is a significant driving force for FDI at level 1\%. As CER has implemented in China for a long time, it is more fruitful compared to other environmental policies. It is easier for such long-term strategic behavior to create innovation compensation, boosting FDI inflows. The impact of MER on FDI at level $1 \%$ is notably negative, the reason for which may be that the short-term collection of pollution-discharge fee squeezes the funds for $\mathrm{R} \& \mathrm{D}$ and technological innovation while causing business costs to rise. As a result, corporate profit is reducing, competitive edge is decreasing, and the FDI attraction is weakening. The effect of PER on FDI is little and significantly negative, the reason for which may be that the form of PER is simple, the legal system is not perfect, and the environmental information publicity is not yet in place.

The estimated results of regional samples show that the impact of different types of environmental regulations on FDI is hugely different. The effect of CER and MER in eastern regions on FDI is larger than that of national overall samples, and the impact of PER on FDI is similar to that of national overall samples. The impact of environmental regulations on FDI in central and western regions is unobvious, and the impact of MER and PER on FDI is gradually weakening from the east to the west, which signifies environmental regulations are not yet a major factor impacting FDI in central and western regions. The empirical results of the control variables shows the factors including economic development, labor cost and trade opening up in central and western regions have stronger impact on FDI than that of environmental regulations. However, the development level of such factors is relatively slower than that of eastern regions, causing weak attraction in central and western regions.

\section{The threshold effect of different types of environmental regulation on FDI}

\subsection{The setting of model}

The impact of different types of environmental regulations in different regions on FDI is various, which can be found by the fixed effect test of environmental regulations on FDI. Thus, there may not be a simple linear relationship between environmental regulations and FDI. With reference to the method of Hansen (1999) ${ }^{13}$, a threshold panel regression model is established based on the impact of CER, MER and PER on FDI, represented by formula (4), (5) and (6), to test the threshold effect of different types of environmental regulations on FDI.

$\ln F D I_{i t}=\beta_{0}+\beta_{11} \ln C E R_{i t} \times I\left(C E R_{i t} \leq \gamma\right)+\beta_{12} \ln C E R_{i t} \times I\left(C E R_{i t}>\gamma\right)+\beta_{2} \ln P G D P_{i t}+$ $\beta_{3} \ln T R A D E_{i t}+\beta_{4} \ln W A G E_{i t}+\varepsilon_{i t}$

$\ln F D I_{i t}=\beta_{0}+\beta_{11} \ln M E R_{i t} \times I\left(M E R_{i t} \leq \gamma\right)+\beta_{12} \ln M E R_{i t} \times I\left(M E R_{i t}>\gamma\right)+\beta_{2} \ln P G D P_{i t}+$ $\beta_{3} \ln T R A D E_{i t}+\beta_{4} \ln W A G E_{i t}+\varepsilon_{i t}$

$\ln F D I_{i t}=\beta_{0}+\beta_{11} \ln P E R_{i t} \times I\left(P E R_{i t} \leq \gamma\right)+\beta_{12} \ln P E R_{i t} \times I\left(P E R_{i t}>\gamma\right)+\beta_{2} \ln P G D P_{i t}+$ $\beta_{3} \ln T R A D E_{i t}+\beta_{4} \ln W A G E_{i t}+\varepsilon_{i t}$

In the formula(4), $C E R_{i t}$ is threshold variables. $I(\cdot)$ is characteristic function. $\gamma$ is threshold value. $\beta_{11}$ and $\beta_{12}$ represent elasticity coefficients of environmental regulations on FDI, 
respectively, when $C E R_{i t} \leq \gamma$ and $C E R_{i t}>\gamma$.If there is threshold effect, the impact of environmental regulations on FDI will be dramatically different under different intensities of environmental regulations. The intensities of MER and PER, namely, $M E R_{i t}$ and $P E R_{i t}$, are set as threshold values in formula (5) and (6), respectively. Moreover, The above is only single threshold model, but there may be multiple thresholds, which can be done in the same manner.

\subsection{Model estimation and testing}

There are two issues to be solved in threshold model. First, threshold value $\gamma$ and all regression variable parameters $\beta$ need to be estimated. Second, correlation test need to be done for threshold value.

The intensities of SER, MER and PER are set as threshold variables in this paper. And bootstrap method is utilized to test the threshold effect of environmental regulations on FDI. The results are as follows. From the national overall level, the three have single threshold values, $0.0550,0.7628$ and 11.5470, respectively. From the respective of eastern, central and western regions, the threshold effect of environmental regulations on FDI is greatly diverse in different regions - the threshold effect in eastern regions is similar to that in national overall samples, but there is no threshold effect of environmental regulations on FDI in central and western regions. As the results in eastern regions are similar to national overall samples, threshold test results and threshold estimated values of national overall samples are selected, listed in table 2 and table 3, respectively.

Table 2 - Significance Test Results of Threshold Variables

\begin{tabular}{|c|c|c|c|c|c|c|}
\hline $\begin{array}{c}\text { Types of } \\
\text { Regulation }\end{array}$ & $\begin{array}{c}\text { the Number } \\
\text { of Threshold }\end{array}$ & Statistics F & Value P & $\begin{array}{c}\text { Critical } \\
\text { Value 1\% }\end{array}$ & $\begin{array}{c}\text { Critical } \\
\text { Value 5\% }\end{array}$ & $\begin{array}{c}\text { Critical Value } \\
10 \%\end{array}$ \\
\hline \multirow{2}{*}{ CER } & $\begin{array}{c}\text { Single } \\
\text { Threshold }\end{array}$ & 21.86 & 0.0320 & 15.9850 & 19.5300 & 26.9109 \\
\cline { 2 - 6 } & $\begin{array}{c}\text { Double } \\
\text { Threshold }\end{array}$ & 13.23 & 0.1240 & 13.9772 & 16.4090 & 23.6919 \\
\hline \multirow{2}{*}{ MER } & $\begin{array}{c}\text { Single } \\
\text { Threshold }\end{array}$ & 24.76 & 0.0000 & 29.2205 & 40.3625 & 54.3145 \\
\cline { 2 - 7 } & $\begin{array}{c}\text { Double } \\
\text { Threshold }\end{array}$ & 9.49 & 0.7880 & 24.7910 & 31.1283 & 45.0320 \\
\hline \multirow{2}{*}{ PER } & $\begin{array}{c}\text { Single } \\
\text { Threshold }\end{array}$ & 24.76 & 0.0740 & 22.4506 & 26.9748 & 36.8591 \\
\cline { 2 - 7 } & $\begin{array}{c}\text { Double } \\
\text { Threshold }\end{array}$ & 9.49 & 0.5220 & 21.8456 & 25.1940 & 42.4025 \\
\hline
\end{tabular}

Note: value P and critical values are gotten through 500 test of bootstrap method.

Table 3- Threshold Estimated Value And Its Confidence Interval

\begin{tabular}{|c|c|c|}
\hline Types of Regulation & Threshold Value & Confidence Interval \\
\hline CER & 0.0550 & {$\left[\begin{array}{ll}0.0542 & 0.0552\end{array}\right]$} \\
\hline MER & 0.7628 & {$\left[\begin{array}{ll}0.7612 & 0.8057\end{array}\right]$} \\
\hline PER & 11.5470 & {$\left[\begin{array}{ll}7.4992 & 11.871\end{array}\right]$} \\
\hline
\end{tabular}

The above 2 tables show that the impact of different types of environmental regulations on FDI all pass significance test of threshold variables. CER passes the single threshold (0.0550) significance test at level 5\%, MER passes the single threshold (0.7628) significance test at level 1\%, and PER passes the single threshold (11.547) significance test at level 10\%. While all the three don't pass double threshold significance test at level 5\%, $1 \%$ and $10 \%$, thus, the original hypothesis of the double threshold is rejected. That is to say, from the respective of 
national overall samples, there is single threshold effect of different types of environmental regulations on FDI.

\subsection{Threshold regression and result analysis}

In line with the above model estimation and test method, empirical analysis of threshold effect is as follows:

\subsubsection{The Impact of CER on FDI}

The impact of different types of environmental regulations on FDI is various, as shown in table 4 . When the intensity of regulations in under 0.055 , the impact of regulations on FDI is significantly positive, which suggests that FDI has a positive role in FDI inflows. "Three simultaneousness" policy, implemented in China for over 30 years, is easier to create incentive effect and will ensure companies to outshine others, making technological innovation actively. However, as enterprise endurance is limited, CER should be within a certain range. When the intensity of environmental regulations is above threshold value, namely, higher than 0.055 , the impact on FDI is negative.

Table 4 - Threshold Regression Result of CER on FDI

\begin{tabular}{|c|c|c|c|c|}
\hline Explanatory Variable & Coefficient & Standard Deviation & Value t & Value P \\
\hline $\operatorname{lnPGDP}$ & 0.7705 & 0.0306 & 25.14 & 0.000 \\
\hline $\operatorname{lnTRADE}$ & 0.4144 & 0.0711 & 5.83 & 0.000 \\
\hline $\operatorname{lnLC}$ & 0.1921 & 0.0290 & 6.63 & 0.000 \\
\hline LnCER(CER $\leq 0.055)$ & 0.0071 & 0.0036 & 1.99 & 0.047 \\
\hline LnCER(CER>0.055) & -0.0037 & 0.0039 & -0.95 & 0.343 \\
\hline _cons & 1.8258 & 0.2651 & 6.89 & 0.000 \\
\hline
\end{tabular}

\subsubsection{The impact of MER on FDI}

Table 5 shows that threshold effect of MER on FDI significantly exists. There is a U-shaped relationship between MER and FDI. Given level 1\%, environmental regulation is negatively related to FDI before the intensity of MER reaches 0.7628 , the reason for which may be that pollution-discharge fees increase corporate cost and squeeze R \& D funds, leaving decreasing company competitiveness. As a result, Some foreign direct investors are turning to invest in the regions with less restrictive environmental regulation. In the long term, when the intensity of environmental regulations is above 0.7628 , the high pollution-discharge fees will lead to increasing corporate cost, which will force companies to introduce new technologies to reduce pollution and encourage them to perfect production process to improve efficiency and profit. With the above efforts, the companies will turn from the short-term crowding out effect to a long-term innovation compensation with competitive edge rising and FDI inflowing. However the standard of pollution-discharge fees is rather low. Some programs is less than $10 \%$ of pollution control costs, leading to no effective incentives for enterprises to reduce pollution and heighten technological innovation. The impact of MER on FDI is on the left side of the U-shaped curve.

Table 5 - Threshold Regression Result of MER on FDI

\begin{tabular}{|c|c|c|c|c|}
\hline Explanatory Variable & Coefficient & Standard Deviation & Value t & Value P \\
\hline $\operatorname{lnPGDP}$ & 0.8512 & 0.0278537 & 30.56 & 0.000 \\
\hline $\operatorname{lnTRADE}$ & 0.3489 & 0.0597771 & 5.84 & 0.000 \\
\hline $\operatorname{lnLC}$ & 0.1332 & 0.0248358 & 5.36 & 0.000 \\
\hline LnMER(MER $\leq 0.7628)$ & -0.0985 & 0.0087487 & -11.26 & 0.000 \\
\hline LnMER(MER>0.7628) & 0.0148 & 0.0053827 & 2.75 & 0.006 \\
\hline _cons & 2.03573 & .223876 & 9.09 & 0.000 \\
\hline
\end{tabular}




\subsubsection{The Impact of PER on FDI}

Table 6 shows that there is a U-shaped relationship between FDI and PER whose impact on FDI is smaller. In the short term, the coefficient of PER on FDI is 0.0173. However, with the weakening of such positive effect and the intensity of PER over 11.547, the coefficient will be 0.0069 - the higher the intensity of PER is, the less FDI will be. At the beginning of PER, the enhanced public awareness of environmental protection and increased environmental letters and visits can encourage enterprises to make innovation and attract FDI inflows. However, with the intensity of PER increasing, the influence of citizens is greater. They can negotiate with companies, go about for their ideas or even affect the corporate reputation and their public image by means of media exposure, environmental rating and the like. The companies are forced to take measures to tackle pollution issues even affecting business performance. Moreover, environmental information in China is not yet in place, which will cause environmental quality information mistakes for the public. They can hardly exercise supervisory right and even misunderstand the environmental information. All the above will leave companies in a passive status. Thus, the impact of PER on FDI is not significant or even negative.

Table 6 - Threshold regression result of PER on FDI

\begin{tabular}{|c|c|c|c|c|}
\hline Explanatory Variable & Coefficient & Standard Deviation & Value t & Value P \\
\hline $\operatorname{lnPGDP}$ & 0.7619 & 0.0287 & 26.53 & 0.000 \\
\hline $\ln$ TRADE & 0.3590 & 0.0678 & 5.30 & 0.000 \\
\hline $\operatorname{lnLC}$ & 0.2091 & 0.0248 & 5.36 & 0.000 \\
\hline $\operatorname{lnPER}(\mathrm{PER} \leq 11.547)$ & 0.0173 & 0.0053 & 3.24 & 0.001 \\
\hline $\operatorname{lnPER}(\mathrm{PER}>11.547)$ & -0.0069 & 0.0016 & -4.29 & 0.000 \\
\hline _cons & 2.0357 & 0.2238 & 9.09 & 0.000 \\
\hline
\end{tabular}

For other control variables, the impact of per capita ( PGDP) on FDI is the greatest and significantly positive, which shows that the higher the economic development level is, the greater attraction to FDI will be. The estimated coefficient of labor cost (WAGE) is also positive, which does not signify that cheap labor cost has become a factor attracting FDI. In fact, Chinese labor costs are relatively low to most investment output countries. And differences in regional wages at present suggest both the differences in labor costs and the differences in labor quality and spending power. The foreign trade level (TRADE) also has a positive effect on FDI. The higher the trade level is, the more open the policies will be and the more FDI will be. FDI in China is mainly from countries and regions featuring market economy and eager to gain investment from economically open countries and regions, so the impact of PER on FDI is positive.

\section{Conclusions and policy inspirations}

The result of this paper shows that the impact of different types of environmental regulations on FDI is hugely various. The existence of "pollution haven" and "porter hypothesis" is relevant to the types and intensities of environmental regulations and different regions. The specific results are as follows.

From the respective of national overall samples, there is threshold effect of different types of environmental regulations on FDI. There is a U-shaped relationship between FDI and CER, MER and PER. However, the impact of PER on FDI is smaller that of CER and MER on FDI. 
From the respective of regional differences, there is spatial heterogeneity in the impact of environmental regulations on FDI.

Based on the above conclusions, the following policy inspirations can be obtained.

(1) Reasonable environmental regulation policies should be developed. Eastern regions should be shifted from CER to MER as the mainstay with PER as the supplement. The role of PER should be fully played. Central and western regions should accelerate economic development, enhance infrastructure and improve market share, creating a favorable environment for FDI inflows and the effective implementation of environmental regulation policy.

(2) The intensity of environmental regulations should be strengthened and the effect of innovation compensation should be developed. The above empirical study shows that the impact of MER on FDI is on the left side of the U-shaped curve, so the intensity of MER on FDI should be upgraded. As enterprise endurance is limited, CER should be within a certain range. So it will become a "booster" for FDI.

(3) The investment strategies should be changed and the policies of attracting foreign investment need to be adjusted. Lucid waters and lush mountains are invaluable assets. Due to the growing issues of environmental pollution, China has been facing a critical moment of changing the "environment for growth" development model and heightens the standard of environmental regulations, strengthening the environmental supervision of FDI enterprises.

\section{References}

1. Xing Y, Kolstad C D. Do Lax Environmental Regulations Attract Foreign Investment?

[J]. Environmental and Resource Economics. 21(2002)1-22.

2. Tao Yang. An Empirical Analysis on the Impact of Environmental Regulation on China 's FDI[J]. World Economy Studies. 5(2003)65-68.

3. Friedman $J$. What attracts foreign multinational corporations? Evidence from branch plant location in the United States[J]. Journal of Regional Science. 1992(32):403-418.

4. Elliott $R J R$, Zhou $Y$. Environmental Regulation Induced Foreign Direct Investment[J]. Environmental and Resource Economics. 55(2013)141-158.

5. HaishengYang,Jia Jia,Yongzhang Zhou etal. Impact on EKC by Trade and FDI in China [J]. China Population, Resources and Environment. 3(2005)99-103.

6. Wheer, D. and A. Mody. International Investment Location Decisions: The Case ofUS Firms[J]. Journal of International Economics. 33(1992)57-76.

7. Javorcik B S, Wei S J. Pollution Havens and FDI: Dirty Secret or Popular Myth? [J]. Contributions in Economic Analysis \& Policy. 3(2003)1244-1244.

8. Xiangang Zeng. Environmental Regulation,FDI and "Pollution Haven” Hypothesis.[J]. Economic Theory and Business Management. 11(2010)65-71. 
9. Co C Y, List J A, Qui L D. Intellectual Property Rights, Environmental Regulations, and Foreign Direct Investment[J]. Land Economics. 80(2004)153-173.

10. Jingyan Fu,Lisha Li. FDI, Environmental Regulation and Pollution Haven EffectEmpirical Analysis of China's Provincial Panel Data [J]. Journal of Public Management. 7(2010)65-74.

11. JunYang,ZhuyaoHe,JianhuiCang. Environmental Regulation,FDI of Manufacturing Industry and Threshold Effect.[J]. On Economic Problems. 11(2016)24-28.

12. Xiuru Mu. A Study on the Nonlinear Relationship between Environmental Regulation and FDI[J]. Modern Management Science. 3(2016)70-72.

13. Hansen, B.E. Threshold Effects in Non-Dynamic Panels: Estimation, Testing and Inference. Journal of Economics. 93(1999)345-368.

14. ZhaoYu-min, Zhu Fang-ming, He Li-long. Definition, Classification and Evolutionof Environmental Regulations [J]. China Population,Resources and Environment. 6(2009)85-90.

15. Zhan Jia, Li Xiu-xiang. Differentiated Impacts of Environmental Regulation Instruments on Technological Innovation [J]. Journal of Guangdong University of Finance \& Economics. 6(2015)16-26.

16. Harbaugh W T,Levinson A,Wilson D M. Reexamining the empirical evidence for an environmental Kuznets curve [J].Review of Economics and Statistics. 84(2002)541551. 